\title{
EGFR inhibitor gefitinib regulates barrier function in human epidermal keratinocytes via the modulation of the expression of claudins
}

\author{
HONG FANG, YINA WANG, LINA XU, SHA ZHOU, JUAN BAI, YINHUA WU, \\ JIANJUN QIAO, XIAOLING JIANG, DINGXIAN ZHU and YINGGUO DING \\ Department of Dermatology, The First Affiliated Hospital, College of Medicine, \\ Zhejiang University, Hangzhou, Zhejiang 310003, P.R. China
}

Received July 2, 2018; Accepted December 18, 2018

DOI: $10.3892 / \mathrm{ijmm} .2018 .4046$

\begin{abstract}
Gefitinib, an epidermal growth factor receptor tyrosine kinase inhibitor, has been frequently used in targeted therapy for lung cancer. However, the widespread use of gefitinib in targeted therapy for patients with lung cancer is hampered by its common skin toxicities. The present study aimed to investigate the mechanisms underlying the skin toxicities of gefitinib. Normal human epidermal keratinocytes (NHEKs) treated with gefitinib were used for a series of in vitro assays, including MTT, reverse transcription-quantitative polymerase chain reaction, western blot analysis, immunohistochemistry and transepithelial electrical resistance and paracellular permeability detection. In the present study, it was determined that the skin toxicities of gefitinib may be due to claudin (CLDN)1 and CLDN4 downregulation and CLDN2 upregulation in NHEKs. Additionally, Src and signal transducer and activator of transcription 3 pathways were involved in gefitinib-induced barrier function disruption in NHEKs. In conclusion, the present study may provide novel insights for improving skin toxicity of gefitinib in patients with lung cancer.
\end{abstract}

\section{Introduction}

Gefitinib, an epidermal growth factor receptor (EGFR) tyrosine kinase inhibitor (TKI) has been frequently used in targeted therapy for lung cancer (1). It is well known that EGFR has widespread expression in normal skin tissues, including the epidermis gland (2). Furthermore, EGFR is important for the development and physiology of the normal epidermis (2).

Correspondence to: Dr Hong Fang, Department of Dermatology, The First Affiliated Hospital, College of Medicine, Zhejiang University, 79 Qingchun Road, Hangzhou, Zhejiang 310003, P.R. China E-mail: fanghongzy@zju.edu.cn

Key words: gefitinib, epidermal growth factor receptor signaling pathway, barrier function, claudins, skin toxicity
However, the clinical application of gefitinib is hampered by common skin toxicities, including papulopustule destruction and skin desquamation (3). These skin toxicities originally occur due to damage to skin barrier function (4). Therefore, in order to optimize the application of gefitinib in patients with lung cancer, the mechanisms underlying skin toxicities of gefitinib should be investigated. Additionally, this field of skin and tumor research is currently attracting substantial interest. In the present study, the aim was to contribute to this field of research.

The epidermis creates a barrier to prevent water loss and the invasion of allergens and infectious agents (5). Claudins (CLDNs) are the most important components of tight junctions (TJs) (5). TJ dysfunction induces aberrant stratum corneum issues by affecting the viability of normal human epidermal keratinocytes (NHEKs) (5). Thus far, 24 CLDN gene family members have been determined in human tissues (5). Previous studies reported that abnormal expression levels of CLDN proteins may impair skin barrier function $(6,7)$. For example, the knockout of CLDN1 in newborn mice resulted in mortality due to the effects of rapid dehydration and apparent skin wrinkles, and the measurement revealed that in these mice the epidermal barrier was severely affected (8). Furthermore, CLDN1 gene mutations were determined in patients with neonatal sclerosing cholangitis (a bile duct obstructive disease) and ichthyosis (9). Additionally, previous study indicated that CLDN2 and 4 were involved in the maintenance of the epidermal barrier function (10). Based on the aforementioned data and the commonly held hypothesis that the EGFR pathway is important in regulating the skin barrier function (11), it is reasonable to speculate that the EGFR pathway may participate in regulating CLDN proteins in skin tissues. This type of regulation may further affect the skin barrier function, which may account for the skin toxicities incurred by gefitinib.

Therefore, exogenous EGF and gefitinib were adopted to interrupt the function of NHEKs by activating or inhibiting the EGFR pathway. Additionally, the viability, transepithelial electrical resistance (TER) and paracellular permeability $(\mathrm{Pa} \%)$ in NHEK were studied. Subsequently, the cell distributions and protein levels of CLDN proteins during the intervention were 
detected in NHEK. Finally, the potential pathways involved in gefitinib-induced barrier function disruption in NHEKs were studied.

\section{Materials and methods}

Reagents. NHEKs were purchased from Cell Applications, Inc., (cat.no. 102K-05a; San Diego, CA, USA). Culture medium and supplements were provided as following: Dulbecco's modified Eagle's medium (DMEM)/F12 medium was purchased from Thermo Fisher Scientific, Inc. (Waltham, MA, USA) and fetal bovine serum (FBS) was purchased from ExCell Biology, Inc. (Shanghai, China). Phosphate buffered saline (PBS), $0.25 \%$ trypsin, 2 mM L-glutamine, poly-D-Lysine coating solution and penicillin-streptomycin were supplied by Hangzhou Best Biotechnology Co., Ltd. (Han Hangzhou, China). EGF was purchased from Thermo Fisher Scientific, Inc. and gefitinib was purchased from Selleck Chemicals (Houston, TX, USA). PP2 (the inhibitor of Src signaling), U0126 [inhibitor of extracellular-signal-regulated kinase (ERK)1/2 signaling] and Stattic [inhibitor of signal transducer and activator of transcription (STAT)3 signaling] were purchased from Sigma-Aldrich; Merck KGaA (Darmstadt, Germany). AZD0530 (inhibitor of Src family tyrosine kinases), GDC-0994 (inhibitor of ERK1/2) and SH-4-54 (STAT inhibitor) were purchased from Selleck Chemicals.

MTT assay. NHEKs were cultured in high-glucose DMEM/F12 medium containing 10\% FBS, 1\% L-glutamine and $1 \%$ penicillin-streptomycin at $37^{\circ} \mathrm{C}$ in an atmosphere containing $5 \% \mathrm{O}_{2}$. A total of $5 \times 10^{4}$ cells/well were cultured on 6-well plates for $24 \mathrm{~h}$ and then treated with $\operatorname{EGF}(0,1,2,5,10$, 15 and $20 \mathrm{ng} / \mathrm{ml})$ or gefitinib $(0,0.1,0.2,0.5,1,1.5$ and $2 \mu \mathrm{M})$ at $37^{\circ} \mathrm{C}$ for another $24 \mathrm{~h}$. Subsequently, the cells were collected and rinsed twice with ice-cold PBS, and then incubated with $100 \mu 10.5 \mathrm{mg} / \mathrm{ml} \mathrm{MTT}$ solution for $3 \mathrm{~h}$ at $37^{\circ} \mathrm{C}$. The resulting crystal was dissolved in $150 \mu$ l dimethyl sulfoxide (DMSO) and the optical density was measured at $570 \mathrm{~nm}$ wavelength using a microplate reader.

TER and Pa\% detection. A total of $2 \times 10^{5}$ NHEKs/well were seeded on a 96-well Transwell plate. Gefitinib and/or EGF were added to the apical or basal compartments of the Transwell inserts when a cell confluence of $85 \%$ was obtained. TER was measured using a EVOM2 voltohmmeter with STX2 electrode (World Precision Instruments, Sarasota, FL, USA) at $24 \mathrm{~h}$. Results were expressed as $\Omega \cdot \mathrm{cm}^{-2}$ and normalized as a percentage of the base-line values.

To measure the paracellular flux of NHEKs, migration experiments were conducted using a Transwell dish at $37^{\circ} \mathrm{C}$. NHEKs were seeded to the upper chamber in serum-free DMEM/F12; the lower chamber contained DMEM/F12 with $10 \%$ FBS. Briefly, Transwells were pre-incubated with Krebs Henselite Bicarbonate buffer (KHBB; pH 7.4; Thermo Fisher Scientific, Inc.) for $15 \mathrm{~min}$ at $37^{\circ} \mathrm{C}$ and washed twice with fresh KHBB. After $24 \mathrm{~h}$, fluorescein isothiocyanate (FITC)-labeled-dextran (FD) dissolved in KHBB (0.1\%) was loaded into the apical or basal compartments of the Transwell inserts. Cells on the upper surface of the filter were removed with a cotton swab. After $2 \mathrm{~h}$ at $37^{\circ} \mathrm{C}, \mathrm{FD}$ intensity of the medium in the apical and basal compartments was determined with a fluorescence spectrophotometer (Hitachi, Ltd., Tokyo, Japan). FITC flux was expressed as the percentage of the apically-added FITC recovered in the basal compartment after $2 \mathrm{~h}$. The measurements aforementioned were produced from four wells/experiment, and the experiments were repeated four times.

Reverse transcription-quantitative polymerase chain reaction $(R T-q P C R)$. Total RNA was isolated using a Qiagen RNAeasy mini kit (Qiagen GmbH, Hilden, Germany), according to the manufacturer's protocols. Complementary DNA (cDNA) was then generated by reverse transcription using a Takara PrimeScript RT Reagent kit (Takara Bio, Inc., Otsu, Japan) according to the manufacturer's protocol. The cDNA was used for RT-qPCR using the SYBR ${ }^{\circledR}$ Premix Ex-Taq ${ }^{\mathrm{TM}}$ kit (TakaraBio, Inc.) on a CFX96 real time PCR system (Bio-Rad Laboratories, Inc., Hercules, CA, USA) according to the manufacturer's protocol. The thermocycling conditions were as follows: Firstly, $94^{\circ} \mathrm{C}$ for $5 \mathrm{~min}$; secondly, $94^{\circ} \mathrm{C}$ for $45 \mathrm{sec}$ and $55^{\circ} \mathrm{C}$ for $30 \mathrm{sec}$; and finally, $72^{\circ} \mathrm{C}$ for $30 \mathrm{sec}$. In total there were 40 thermal cycles. The $2{ }^{-{ }^{\Delta}} \mathrm{Cq}$ method was used to calculate the relative gene expression (12). All expression data were normalized to human $\beta$-actin (ACTB). Primers sequences were provided as follows: EGFR forward, 5'-TGACTGAGGACAGCATAGACGA-3' and reverse, 5'-GGGCTGGACAGTGTTGAGATAC-3'; CLDN1 forward, 5'-CATTGGTGTCTGGAGACCTG-3' and reverse, 5'-AATGCCTTGCTCAAACACAG-3'; CLDN2 forward, 5'-TAAGAAGCCAGGTGGATGTG-3' and reverse, 5'-CGC CTGAAGAGTTTCTAGGG-3'; CLDN4 forward, 5'-AAC CCTGACTTTGGGATCTG-3' and reverse, 5'-AGATGC AGGCAGACAGAGTG-3'; ERK1 forward, 5'-TCCATC GACATCTGGTCTGT-3' and reverse, 5'-TGAGCT GATCCAGGTAGTGC-3'; ERK2 forward, 5'-CCGTGACCT CAAGCCTTC-3' and reverse, 5'-GCCAGGCCAAAG TCACAG-3'; and ACTB forward, 5'-TCCTTCCTGGGC ATGGAGT-3' and reverse, 5'-CAGGAGGAGCAATGATCT TGAT-3'.

Immunoblotting. A total of $5 \times 10^{4} \mathrm{NHEKs} /$ well were cultured on 6-well plates for $24 \mathrm{~h}$ at $37^{\circ} \mathrm{C}$, and then treated with EGF or gefitinib at $37^{\circ} \mathrm{C}$ for another $24 \mathrm{~h}$. Next, cultured cells were rinsed with ice-cold PBS and then lysed in radioimmunoprecipitation assay buffer at $4^{\circ} \mathrm{C}$ for $10 \mathrm{~min}$ (Cell Signaling Technology, Inc., Danvers, MA, USA) containing complete protease inhibitors and phosphatase inhibitors (Roche Diagnostics, Indianapolis, IN, USA), $5 \mathrm{mM}$ dithiothreitol and $1 \mathrm{mM}$ phenylmethylsulfonyl fluoride (Sigma Aldrich; Merck $\mathrm{KGaA}$ ). Protein concentrations in the resulting supernatants were determined using a Bio-Rad protein assay (Bio-Rad Laboratories, Inc.). Aliquots containing $40 \mu \mathrm{g}$ total proteins were loaded and separated by $8 \%$ SDS-PAGE, and then transferred to a polyvinylidene fluoride membrane (PVDF; EMD Millipore, Billerica, MA, USA). Subsequently, the PVDF membrane was blocked using 5\% skim milk in tris-buffered saline with $0.5 \%$ Tween-20 (Sigma-Aldrich; Merck KGaA) at room temperature for $1 \mathrm{~h}$, the membranes were incubated overnight at $4{ }^{\circ} \mathrm{C}$ with primary antibodies. The primary antibodies were as follows: Anti-phospho (p)-EGFR (1:1,000; cat. no. ab134005), anti-Src (1:1,000; cat. no. ab47405), 
anti-p-Src (1:1,000; cat. no. ab40660), anti-STAT3 (1:1,000; cat. no. ab119352), anti-p-STAT3 (1:1,000; cat. no. ab76315), anti-ERK1/2 (1:1,000; cat. no. ab17942), anti-p-ERK1/2 (1:1,000; cat. no. ab214362), anti-CLDN 1 (1:1,000; cat. no. ab15098), anti-CLDN 2 (1:1,000; cat. no. ab53032), anti-CLDN 4 (1:1,000; cat. no. ab53156) and anti-ACTB $(1: 1,000$; cat. no. ab8227) were provided by Abcam (Cambridge, UK). Next, the membranes were incubated with goat anti-mouse horseradish peroxidase-conjugated secondary antibodies (1:5,000; cat. no. ab97040) at room temperature for $1 \mathrm{~h}$. Finally, the PVDF membranes were incubated with enhanced chemiluminescence reagent (Santa Cruz Biotechnology, Inc., Dallas, TX, USA) to detect the blots. The images from the western blot analysis assay were analyzed using Quantity One 1-D (Bio-Rad Laboratories, Inc.).

Immunohistochemistry. A total of $5 \times 10^{4}$ NHEKs/well were cultured on 6-well plates for $24 \mathrm{~h}$ and then treated with EGF or gefitinib at $37^{\circ} \mathrm{C}$ for another $24 \mathrm{~h}$. After that, cultured cells were plated on poly-D-lysine-coated coverslips were rinsed twice with PBS and fixed with $4 \%$ paraformaldehyde for $30 \mathrm{~min}$ at room temperature. Cells were then washed 3 times with PBS, permeabilized in $0.4 \%$ Triton X-100 for 10 min and blocked for $1 \mathrm{~h}$ at room temperature in PBS with $0.5 \%$ Tween-20 containing $4 \%$ bovine serum albumin (Bio-Rad Laboratories, Inc.). Following overnight incubation at $4^{\circ} \mathrm{C}$ with the indicated primary antibodies (Abcam): Anti-CLDN 1 (1:1,000; cat. no. ab15098), anti-CLDN 2 (1:1,000; cat. no. ab53032) and anti-CLDN 4 (1:1,000; cat. no. ab53156), cells were washed with PBS three times for 10 min each and then incubated for $2 \mathrm{~h}$ at room temperature with FITC/tetramethylrhodamine-conjugated goat anti-mouse secondary antibodies (1:5,000; cat. no. ab97040; Abcam). Cells were exposed to $0.5 \mu \mathrm{g} / \mathrm{ml}$ DAPI (Sigma-Aldrich; Merck KGaA) for $5 \mathrm{~min}$ at $37^{\circ} \mathrm{C}$. The coverslips were mounted using Fluoromount Aqueous Mounting medium (Sigma Aldrich; Merck KGaA) and imaged using an Olympus Fluoview FV1000 confocal laser scanning microscope. Raw images were analyzed using the Olympus FV10-ASW 2.1 Viewer software (magnification x400; Olympus Corporation, Tokyo, Japan).

Cell signalling pathways. In order to further investigate the potential pathways involved in NHEK endothelial barrier function, NHEKs were treated at $37^{\circ} \mathrm{C}$ for $24 \mathrm{~h}$ with different treatments as follows: i) $5 \mathrm{ng} / \mathrm{ml} \mathrm{EGF}$; ii) $5 \mathrm{ng} / \mathrm{ml}$ EGF $+10 \mu \mathrm{M}$ PP2 (the inhibitor of the Src pathway); iii) $5 \mathrm{ng} / \mathrm{ml}$ EGF $+10 \mu \mathrm{M}$ U0126 (the inhibitor of the ERK1/2 pathway); iv) $5 \mathrm{ng} / \mathrm{ml} \mathrm{EGF}+20 \mu \mathrm{M}$ Stattic (the inhibitor of the STAT3 pathway); and v) $5 \mathrm{ng} / \mathrm{ml}$ EGF $+1 \mu \mathrm{M}$ gefitinib; or vi) DMSO (as a control). According to the manufacturer, $10 \mu \mathrm{M}$ PP2, $10 \mu \mathrm{M} \mathrm{U} 0126$ or $20 \mu \mathrm{M}$ Stattic exert an inhibitory effect on Src, ERK or STAT3, respectively. Following incubation with these inhibitors, the cells were collected and the total protein was extracted, and then a western blot assay was applied as described above to detect the expression of following proteins: p-EGFR, EGFR, Src, p-Src (Y418), STAT3, p-STAT3 (Y705), ERK1/2, p-ERK1/2, CLDN1, CLDN2 and CLDN4.

Statistical analysis. Unless indicated otherwise, results are presented as the mean \pm standard deviation. Statistical analyses were conducted using a one-way analysis of variance followed by a Dunnett's test using the software SPSS v.19.0 (IBM Corp., Armonk, NY, USA). P $<0.05$ was considered to indicate a statistically significant difference.

\section{Results}

Effects of EGF or/and gefitinib on NHEK cell viability. It has been reported that EGFR signaling is involved in the function of the skin barrier (11). In order to determine the functions of the EGFR pathway on the skin barrier function, NHEKs were treated withEGFor gefitinib and the cell viability and the expression of p-EGFR were detected. As depicted in Fig. $1 \mathrm{~A}$ and B, the cell viability was significantly increased by 2,5 and $10 \mathrm{ng} / \mathrm{ml}$ EGF compared with the control group $(\mathrm{P}<0.05)$ with $5 \mathrm{ng} / \mathrm{ml}$ EGF inducing peak cell viability $(\mathrm{P}<0.01)$, while $>1 \mu \mathrm{M}$ gefitinib demonstrated a significant dose-dependent inhibitory effect on cell viability $(\mathrm{P}<0.05)$. Additionally, the results of the western blot analysis demonstrated that the protein levels of p-EGFR in NHEKs were significantly increased with 2 and $5 \mathrm{ng} / \mathrm{ml}$ EGF compared with the control group $(\mathrm{P}<0.05)$, and peaked at $5 \mathrm{ng} / \mathrm{ml}$ EGF $(\mathrm{P}<0.01$; Fig. $1 \mathrm{C}$ and $\mathrm{D})$. By contrast, $2 \mu \mathrm{M}$ gefitinib exerted the most significant inhibitory effect on p-EGFR levels in the NHEK compared with the control group ( $\mathrm{P}<0.01$; Fig. $1 \mathrm{C}$ and E); therefore, $5 \mathrm{ng} / \mathrm{ml}$ EGF and $2 \mu \mathrm{M}$ gefitinib were selected for subsequent experiments. Furthermore, EGF was able to significantly partly reverse gefitinib-induced NHEK cell growth inhibition $(\mathrm{P}<0.05$; Fig. $1 \mathrm{~F})$.

Effects of gefitinib on the cell barrier functions of NHEK. Subsequently, the cell barrier functions of NHEK were monitored by detecting TER and Pa\%. Compared with the control group, gefitinib significantly reduced cell resistance from $195.58 \pm 7.84$ to $147.36 \pm 21.94(\mathrm{P}<0.01$; Fig. $2 \mathrm{~A})$ and significantly increased $\mathrm{Pa} \%$ from $1.00 \pm 0.03$ to $1.78 \pm 0.06$ $(\mathrm{P}<0.01$; Fig. $2 \mathrm{~B})$ in NHEK. In contrast, EGF notably increased TER $(292.62 \pm 20.54$ vs $195.58 \pm 7.84$; P<0.01; Fig. 2A) and significantly decreased $\mathrm{Pa} \%(0.85 \pm 0.03$ vs $1.00 \pm 0.03$; $\mathrm{P}<0.01$; Fig 2B) in NHEK compared with the control group. Furthermore, the effects of gefitinib on TER $(\mathrm{P}<0.05)$ and $\mathrm{Pa} \%(\mathrm{P}<0.01)$ were significantly reversed by EGF treatment in NHEK (Fig.2A and B).

Effects of gefitinib on the expression levels and cellular distributions of CLDNs in NHEK. Since CLDNs are important components of cell $\mathrm{TJ}$ (13), their expression and localization were analyzed in NHEK. The RT-qPCR and western blot analysis results demonstrated that EGF significantly increased CLDN1 and 4 expression $(\mathrm{P}<0.01)$, and decreased CLDN2 $(\mathrm{P}<0.01)$, compared with the controls. By contrast, gefitinib significantly downregulated the levels of CLDN1 and $4(\mathrm{P}<0.01)$ and significantly upregulated the levels of CLDN2 $(\mathrm{P}<0.01)$ compared with the controls (Fig. 3A and B). Furthermore, the localization of CLDNs in NHEK demonstrated the corresponding changes (Fig. 3C). CLDN1 became more enriched in the nucleus of NHEK following EGF treatment (Fig. 3C-2), whereas CLDN4 accumulated in the cytoplasm (Fig. 3C-5). By contrast, the fluorescent intensities of CLDN1 and 4 were diminished, while CLDN2 was enhanced in the nucleus and cytoplasm (Fig. 3C-3, C-6 and C-9) in gefitinib-treated NHEK. 
A

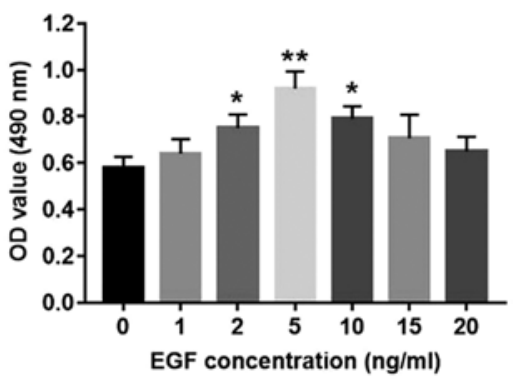

EGF concentration $(\mathrm{ng} / \mathrm{ml})$
B

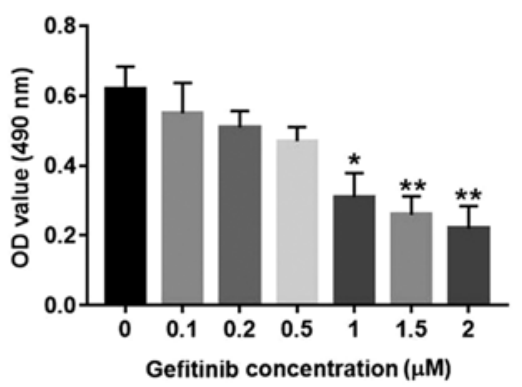

C
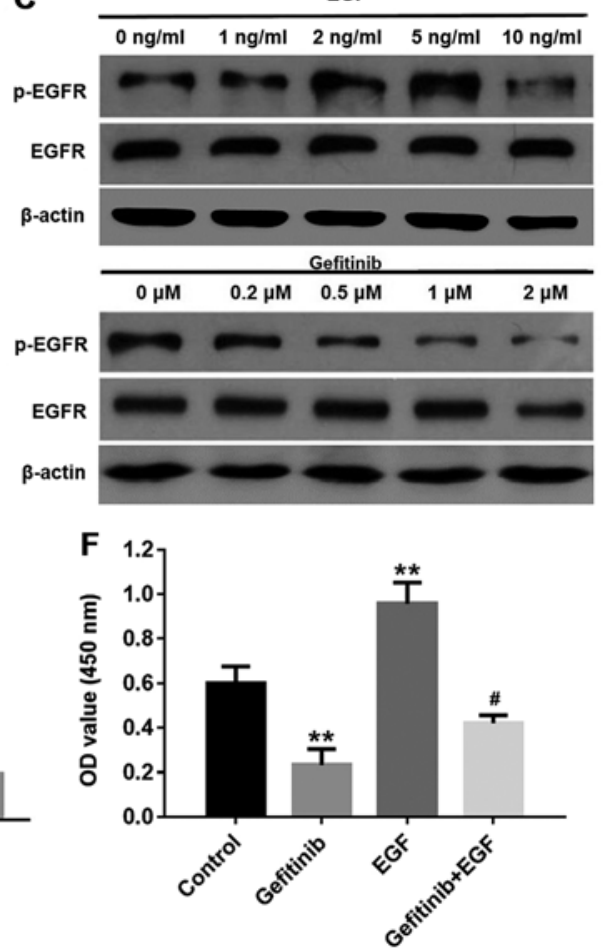

Figure 1. Effects of EGF or/and gefitinib on NHEK cell viability. (A) NHEK were treated with $0,1,2,5,10,15$ or $20 \mathrm{nM}$ EGF for $24 \mathrm{~h}$ and the cell viability was detected with an MTT assay. ${ }^{*} \mathrm{P}<0.05$ and ${ }^{* *} \mathrm{P}<0.01$ vs. the control group, $\mathrm{n}=3$. (B) NHEK were treated with $0,0.1,0.2,0.5,1,1.5$ or $2 \mu \mathrm{M}$ gefitinib for $24 \mathrm{~h}$. ${ }^{*} \mathrm{P}<0.05$ and $^{* *} \mathrm{P}<0.01$ vs. the control group, $\mathrm{n}=3$. (C) Protein expression of $\mathrm{p}$-EGFR was investigated by western blot analysis in NHEK following treatment with EGF or gefitinib for $24 \mathrm{~h}$. (D) Relative expression levels of p-EGFR were quantified following treatment with EGF. ${ }^{*} \mathrm{P}<0.05$ and ${ }^{* * *} \mathrm{P}<0.01$ vs. the control group, $n=3$. (E) Relative expression levels of $p$-EGFR were quantified following treatment with gefitinib. ${ }^{*} \mathrm{P}<0.05$ and ${ }^{* *} \mathrm{P}<0.01$ vs. the control group, $\mathrm{n}=3$. (F) NHEK were treated with $2 \mu \mathrm{M}$ gefitinib and/or $5 \mathrm{nM}$ EGF for $24 \mathrm{~h}$ and the cell viability was detected with an MTT assay. ${ }^{* *} \mathrm{P}<0.01$ vs. the control group, ${ }^{\text {\#}} \mathrm{P}<0.05$ vs. gefitinib group, $\mathrm{n}=3$. NHEK, normal human epidermal keratinocytes; EGF, epidermal growth factor; EGFR, epidermal growth factor receptor; $\mathrm{p}-$, phosphorylated.
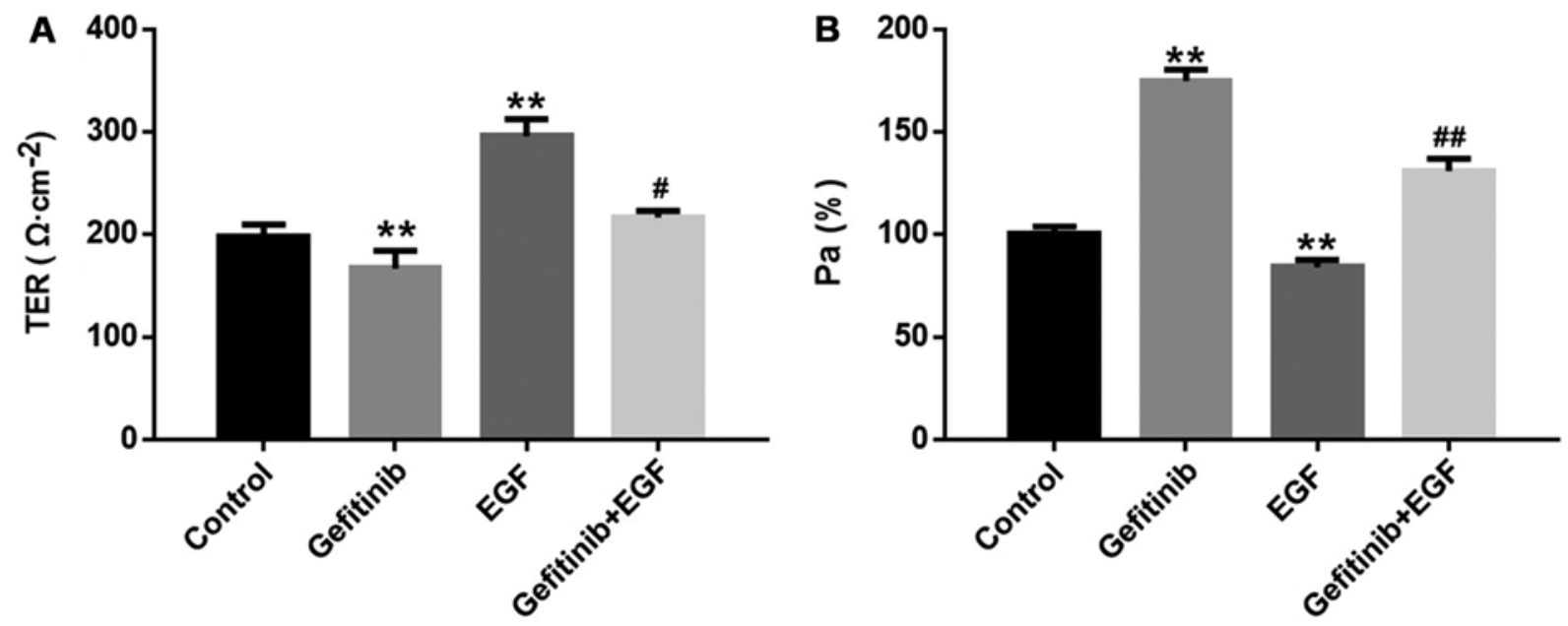

Figure 2. Effects of gefitinib and/or EGF on TER and Pa\% in NHEK. (A) NHEK were treated with gefitinib and/or EGF for $24 \mathrm{~h}$, and the TER was detected. ${ }^{* *} \mathrm{P}<0.01$ vs. the control group; ${ }^{\#} \mathrm{P}<0.05$ vs. the gefitinib group; $\mathrm{n}=3$. (B) NHEK were treated with gefitinib and/or EGF for $24 \mathrm{~h}$, and the Pa\% was detected. ${ }^{* *} \mathrm{P}<0.01$ vs. the control group; ${ }^{\# \#} \mathrm{P}<0.01$ vs. the gefitinib group; $\mathrm{n}=3$. EGF, epidermal growth factor; NHEK, normal human epidermal keratinocytes; TER, transepithelial electrical resistance; $\mathrm{Pa} \%$, paracellular permeability.

These changes may be associated with gefitinib-induced barrier function disruption in NHEK.

Investigation of the potentially involved pathways. It has been reported that Src, ERK and STAT3 may serve a function as regulators of the endothelial barrier func- tion $(14,15)$. In order to further investigate if these pathways were involved, different specific inhibitors were applied. As depicted in Fig. 4A-E, PP2, U0126, Stattic and gefitinib exerted a significant inhibitory effect on their respective targets in NHEK compared with the control groups $(\mathrm{P}<0.01)$. Furthermore, EGF-induced CLDN1 and CLDN4 upregula- 

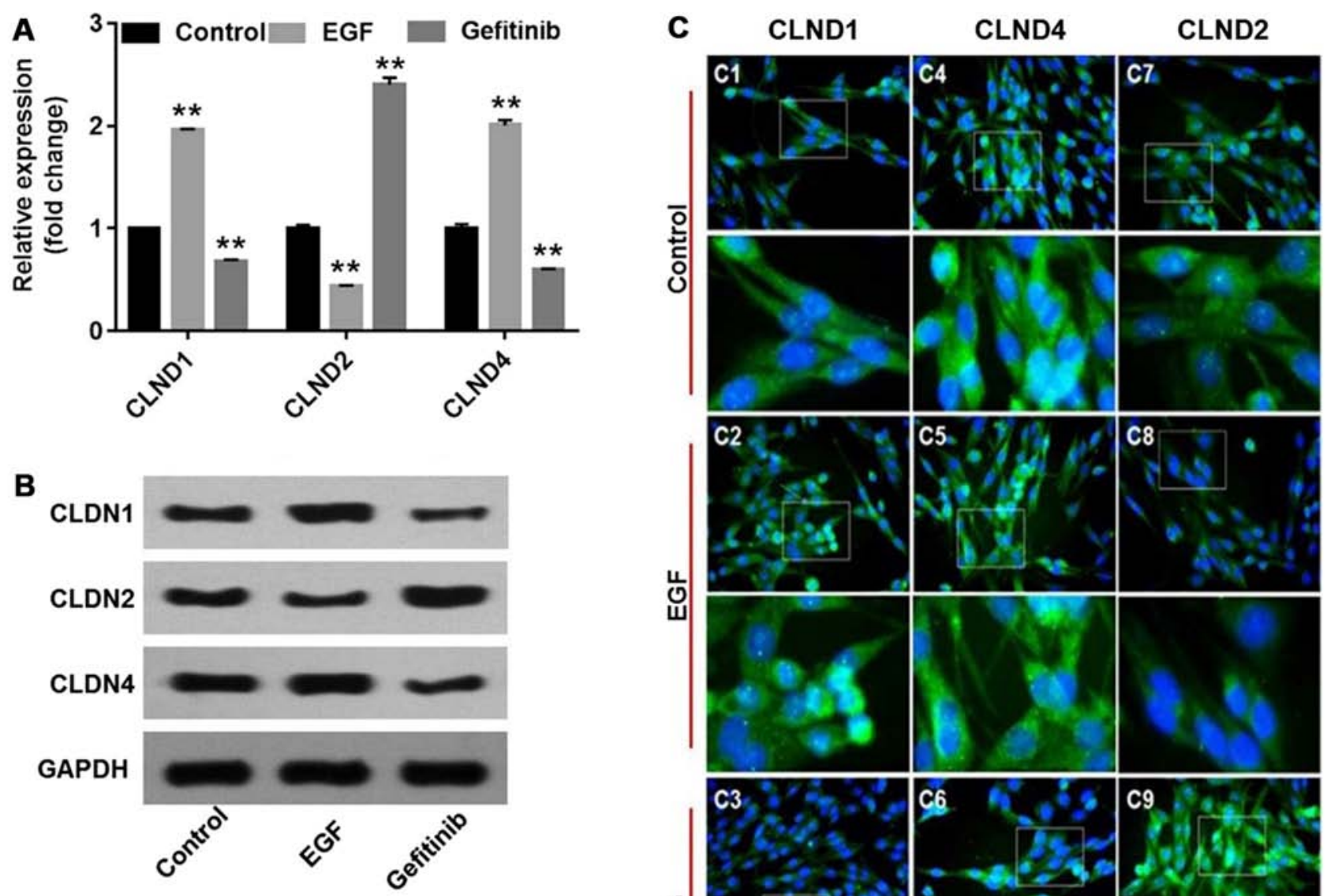

嵌
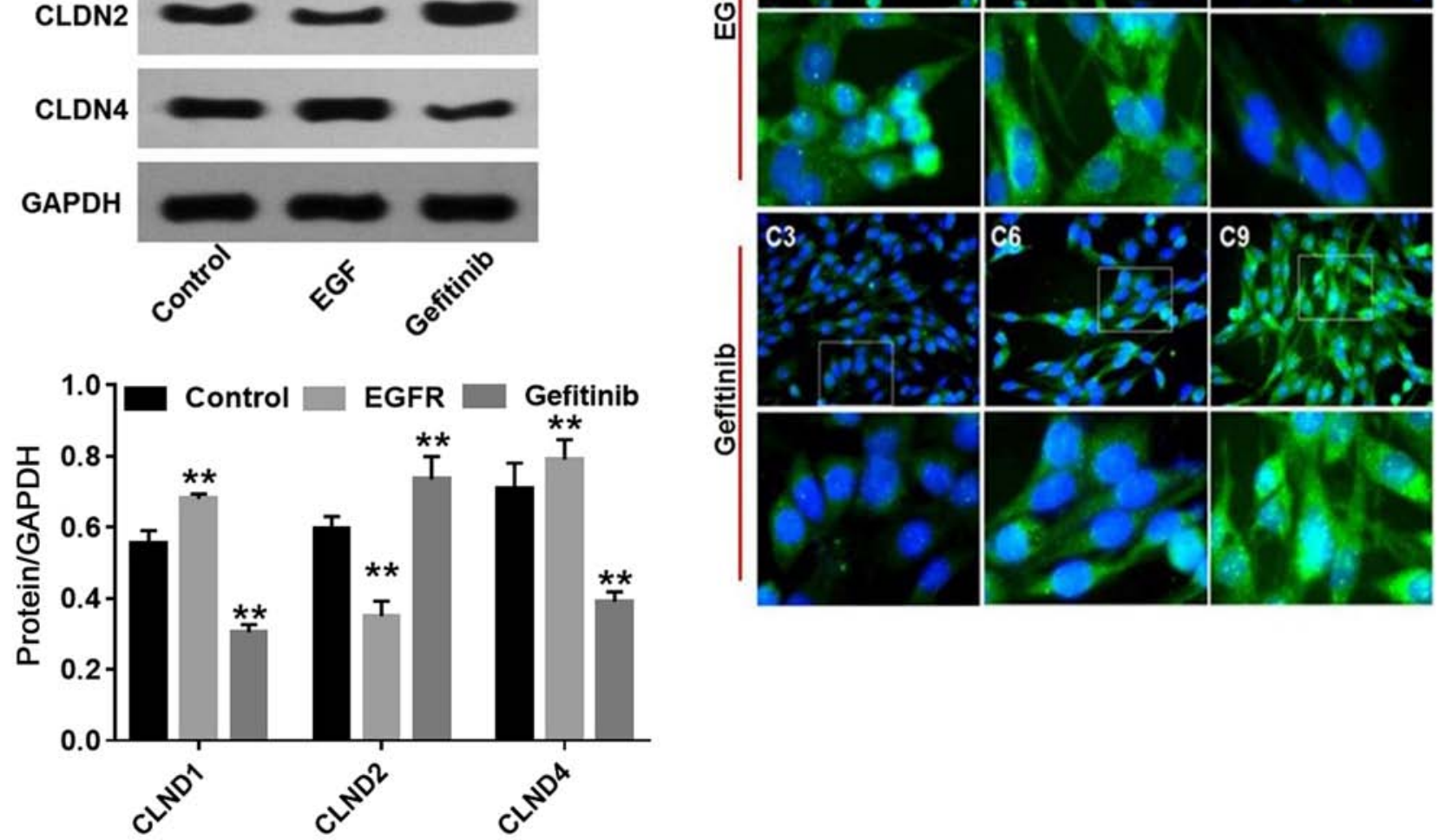

Figure 3. Effects of EGF or gefitinib on the expression levels, cellular distributions and activation of CLDN1, 2 and 4. NHEK were treated with gefitinib or EGF for $24 \mathrm{~h}$. (A) mRNA levels of CLDN1, 2 and 4 were detected with reverse transcription-quantitative polymerase chain reaction. ${ }^{* * *}<0.01$ vs. the control group, $\mathrm{n}=3$. (B) Protein levels of CLDN1, 2 and 4 were detected with western blot analysis. ${ }^{* *} \mathrm{P}<0.01$ vs. the control group, $\mathrm{n}=3$. (C) Cellular distributions of CLDN1, 2 and 4 were measured using an immunohistochemistry assay. EGF, epidermal growth factor; NHEK, normal human epidermal keratinocytes; CLDN, claudin

tion and CLDN2 downregulation may be partially reversed by PP2, U0126 or Stattic, compared with the EGF treatment group. (Fig. 4A and F-H). Consistently, western blot analysis (Fig. 5) demonstrated that EGF-induced CLDN1 (Fig. 5B) and CLDN4 upregulation (Fig. 5D) and CLDN2 downregulation (Fig. 5C) was reversed by another Src inhibitor (AZD0530), ERK1/2 inhibitor (GDC-0994) or STAT3 inhibitor (SH-4-54), respectively. Additionally, the expression levels of p-Src and p-STAT3 were significantly inhibited by gefitinib in NHEK compared with the control cells $(\mathrm{P}<0.01$; Fig. 6A-C). These data indicated that the Src and STAT3 pathways were involved in gefitinib-induced barrier function disruption in NHEK (Fig. 6D).

\section{Discussion}

Since NHEK are frequently used as model cells to study the functions of the skin cell barrier (16-20), they were also used in the present study. In the present study, it was firstly observed that exogenous gefitinib was able to damage the cell barrier function via inhibiting the EGFR, Src and STAT3 pathways, accompanied by regulating the expression of CLDN proteins. Furthermore, all these effects, caused by gefitinib, may be reversed by treatment with EGF. EGF has been previously known to increase the TER of epithelial LLCPK1 cells (21). The effects of EGF on TER or regulation of CLDN proteins have previously been investigated in renal carcinoma (MDCK 

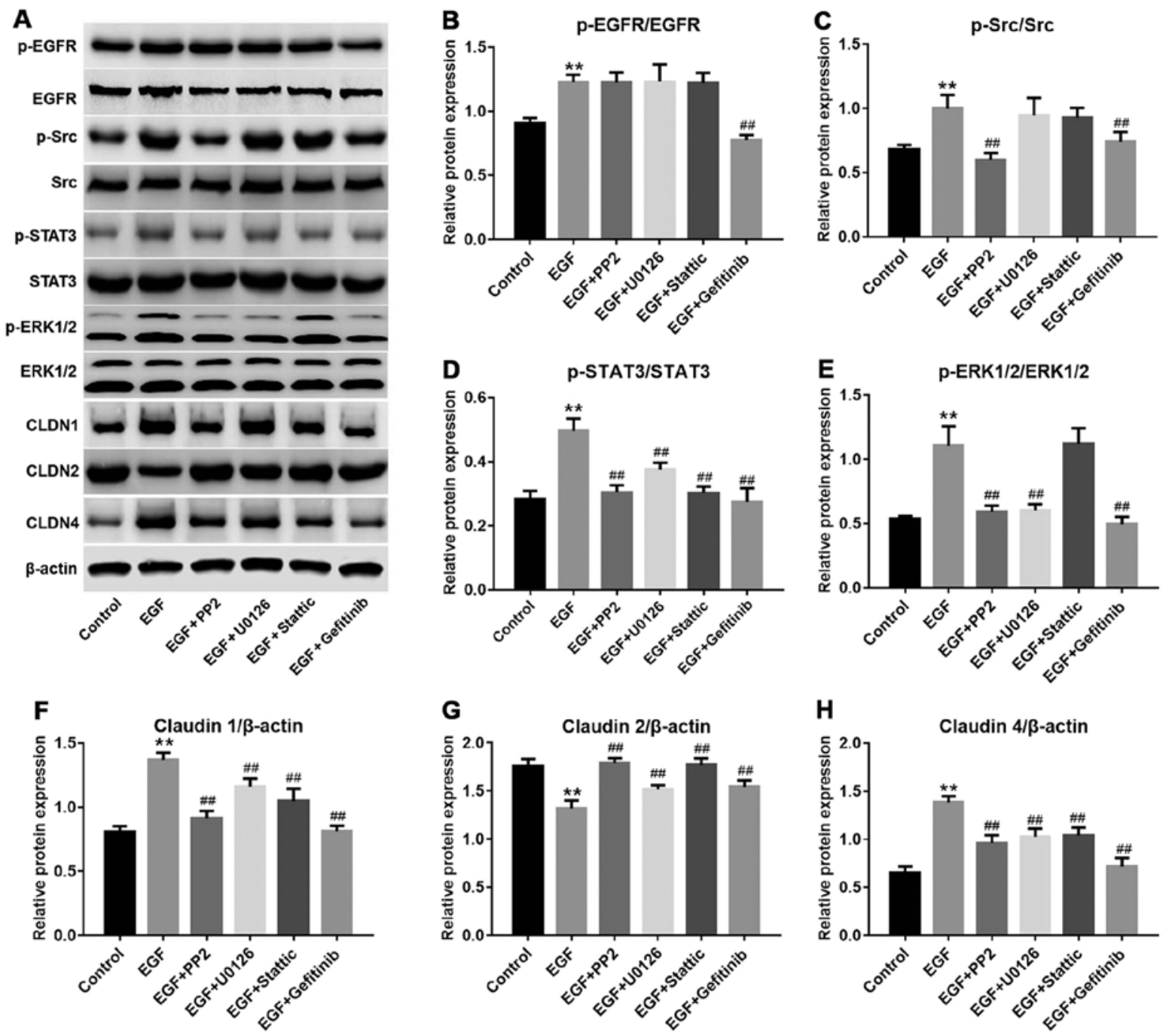

Figure 4. EGF-induced Src and STAT3 pathway activation were reversed by gefitinib. (A) Representative images of western blot analysis for proteins in different groups. (B) Protein levels of p-EGFR were detected with western blot analysis. ${ }^{* *} \mathrm{P}<0.01$ vs. the control group; ${ }^{\#} \mathrm{P}<0.01$ vs. the EGF group, $\mathrm{n}=3$. (C) Protein levels of p-Src were detected with western blot analysis. ${ }^{* *} \mathrm{P}<0.01$ vs. the control group; ${ }^{\# \#} \mathrm{P}<0.01$ vs. the EGF group, $\mathrm{n}=3$. (D) Protein levels of p-STAT3 were detected with western blot analysis. ${ }^{* *} \mathrm{P}<0.01$ vs. the control group; ${ }^{\# \#} \mathrm{P}<0.01$ vs. the EGF group, $\mathrm{n}=3$. (E) Protein levels of $\mathrm{p}$-ERK were detected with western blot analysis. ${ }^{* *} \mathrm{P}<0.01$ vs. the control group; ${ }^{\# \#} \mathrm{P}<0.01$, vs the EGF group, $\mathrm{n}=3$. (F) Protein levels of CLND1 were detected with western blot analysis. ${ }^{* *} \mathrm{P}<0.01$ vs. the control group; ${ }^{\# /} \mathrm{P}<0.01$ vs. the EGF group, $\mathrm{n}=3$. (G) Protein levels of CLND2 were detected with western blot analysis. ${ }^{* *} \mathrm{P}<0.01$ vs. the control group; ${ }^{\# \prime} \mathrm{P}<0.01$ vs. the EGF group, $\mathrm{n}=3$. (H) Protein levels of CLND4 were detected with western blot analysis. ${ }^{* *} \mathrm{P}<0.01$ vs. the control group; ${ }^{\# \#} \mathrm{P}<0.01$ vs. the EGF group, $n=3$. EGF, epidermal growth factor; NHEK, normal human epidermal keratinocytes; STAT3, signal transducer and activator of transcription 3. CLDN, claudin; p-, phosphorylated; EGFR, epidermal growth factor receptor.

cells). Flores-Benitez et al (22), reported that CLDN1, 3 and 4 proteins may be upregulated in MDCK cells by EGF, and that the downstream ERK signaling pathway served a notable role in the process of regulating the kidney $\mathrm{Pa} \%$. The present results are in agreement with these data.

EGF or gefitinib regulate the changes in the composition of TJ (notably, affecting CLDN1, 2 and 4) through a number of mechanisms $(23,24)$. CLDN2 is necessary for TJ strand formation (25). It is able to form cation and water-selective channels, and is necessary for the uptake of $\mathrm{Na}^{+}$, water and $\mathrm{Ca}^{2+}$ (26-28). Therefore, CLDN2 is responsible for the low TER phenotype of cells (29). In contrast, CLDN1 and 4 are involved in the structure formation of epidermal TJ (10). CLDN4 was demonstrated to confer a high resistance phenotype in epithelial cells $(30,31)$. Consequently, the enhancement of the cell barrier function may be achieved by reducing CLDN2 and augmenting CLDN1 and 4 levels (32).
The present results demonstrated that gefitinib may disrupt cell barrier function by decreasing the expression of CLDN1 and 4 and increasing the expression of CLDN2 (Fig. 3). In terms of the mechanism, previous studies have reported that EGF activated ERK1/2, which in turn may downregulate CLDN2 and upregulate CLDN1, 3 and 4 at TJ (33-35). A similar change in ERK $1 / 2$ activity was observed following treatment with gefitinib in NHEK.

Notably, the present study was performed in NHEK in vitro. Considering the sophisticated environment in vivo, further experiments are required to evaluate the effect of gefitinib on the skin barrier function and the potential involvement of signaling molecules, including Src or STAT3, in animal models $(36,37)$. Additionally, the present study indicated that gefitinib was capable of damaging the skin cell barrier function by regulating the protein levels of CLDN1, 2 and 4 . The present study will be notably beneficial for the continued investigation 
A
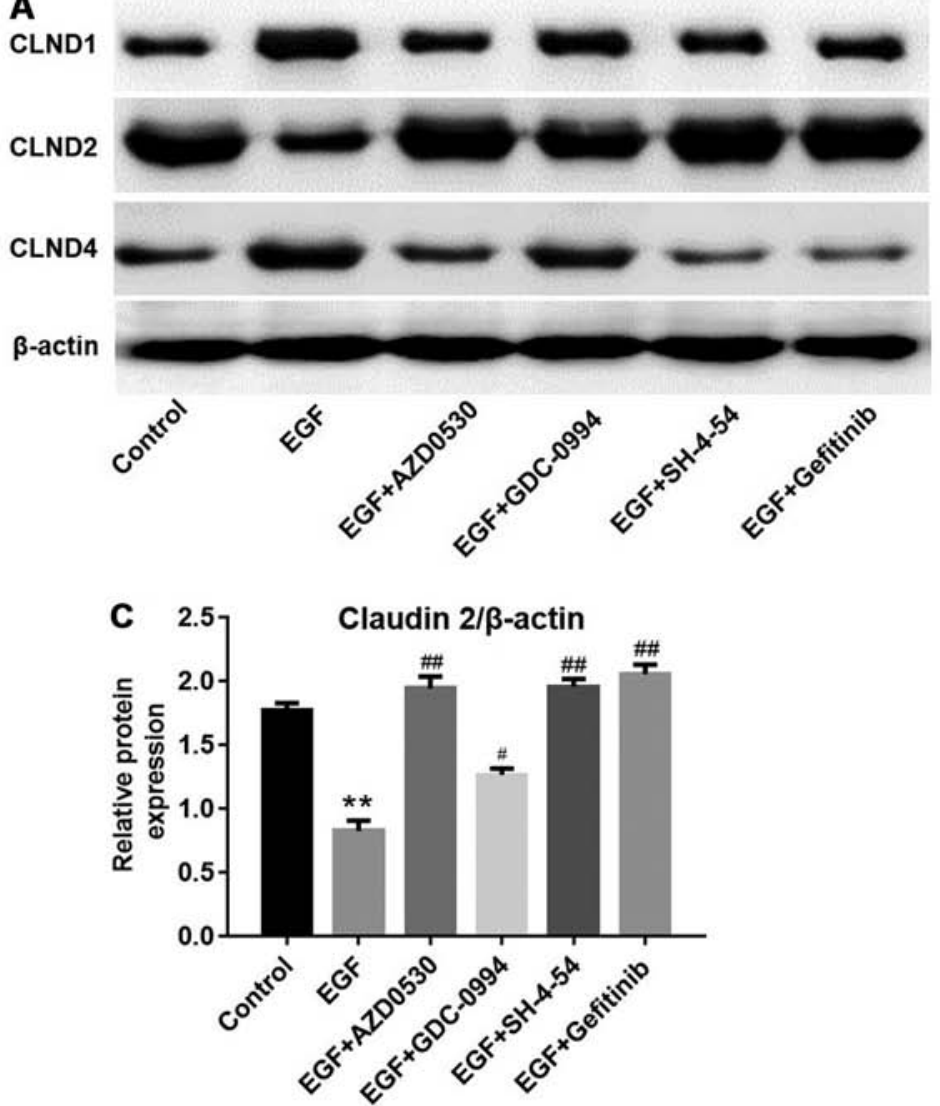

\section{B $\left.\quad{ }^{2.0}\right] \quad$ Claudin $1 / \beta$-actin}
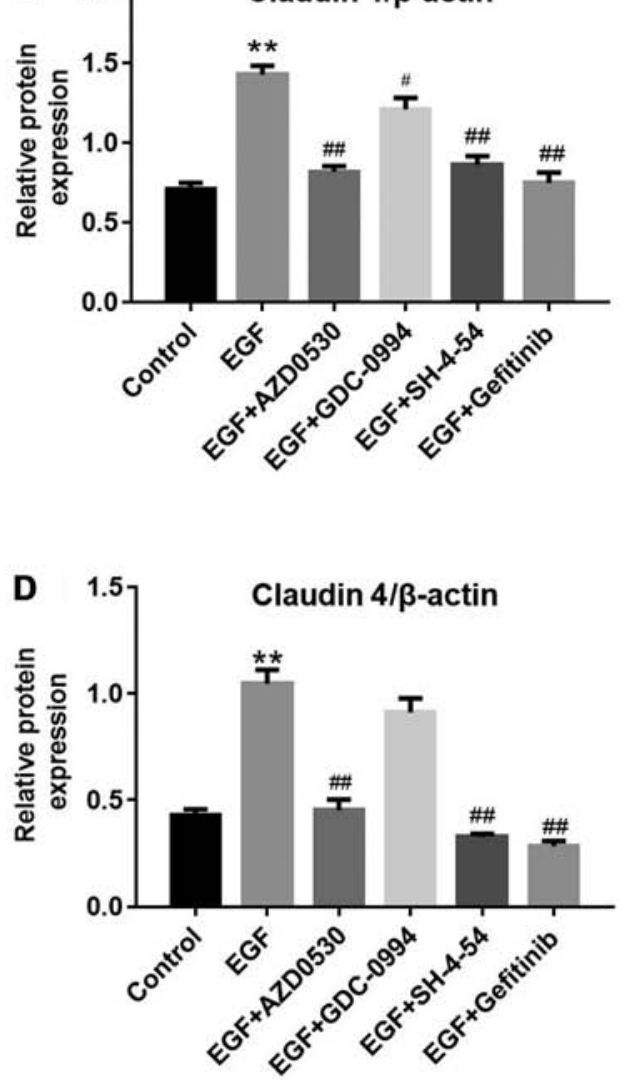

Figure 5. EGF-induced Src and signal transducer and activator of transcription 3 pathway upregulation were reversed by gefitinib. (A) Representative images of western blot analysis for proteins in different groups. (B) Protein levels of CLND1 were detected with western blot analysis. ${ }^{* *} \mathrm{P}<0.01 \mathrm{vs}$. the control group; ${ }^{\#} \mathrm{P}<0.05$ and ${ }^{\# \#} \mathrm{P}<0.01$, vs the EGF group, $\mathrm{n}=3$. (C) Protein levels of CLND2 were detected with western blot analysis. ${ }^{* *} \mathrm{P}<0.01$ vs. the control group; ${ }^{\#} \mathrm{P}<0.05$ and ${ }^{\#} \mathrm{P}<0.01$, vs the EGF group, $\mathrm{n}=3$. (D) Protein levels of CLND4 were detected with western blot analysis. ${ }^{* *} \mathrm{P}<0.01$ vs. the control group; ${ }^{\# \#} \mathrm{P}<0.01 \mathrm{vs}$ the EGF group, n=3. EGF, epidermal growth factor; NHEK, normal human epidermal keratinocytes; CLDN, claudin.

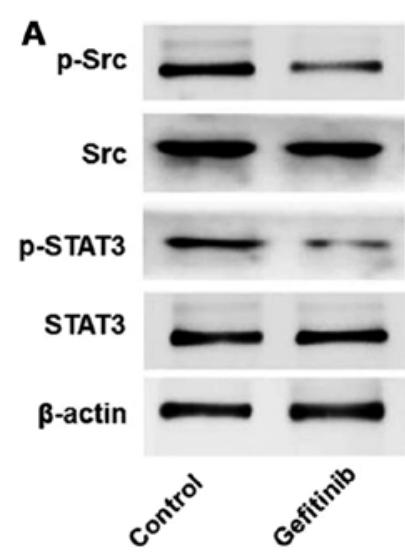

D
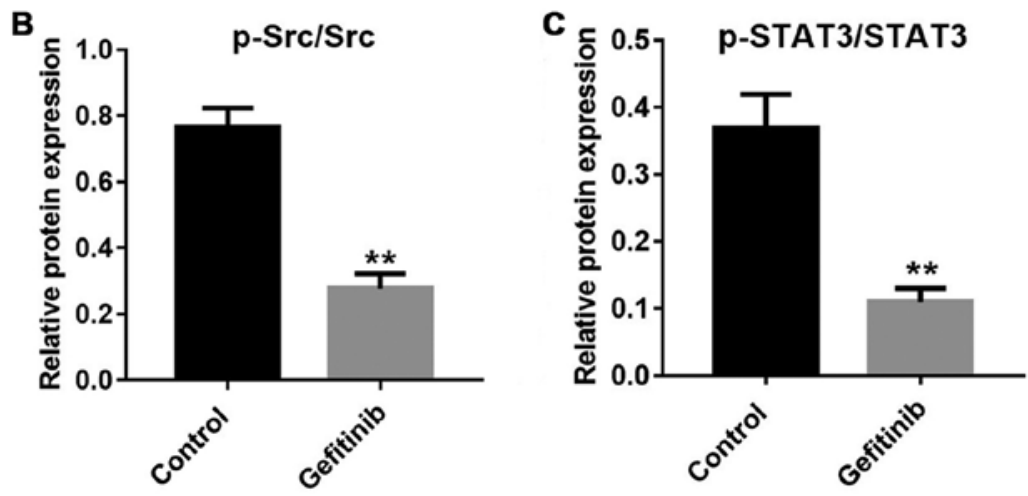

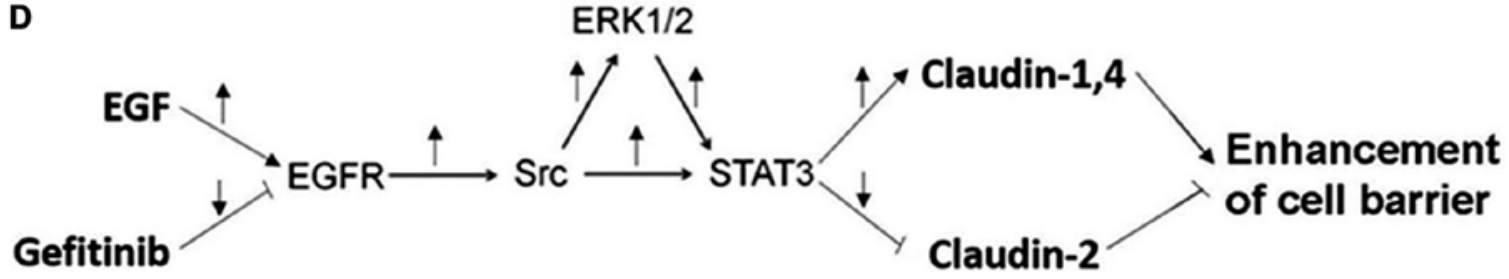

Figure 6. Gefitinib-induced barrier function disruption in NHEK is partially due to inhibition of the Src and STAT3 pathways. (A) NHEK were treated with gefitinib for $24 \mathrm{~h}$ and the protein expression levels of p-Src and p-STAT3 were detected with western blot analysis. (B) Quantification of the protein expression levels of p-Src in NHEK. (C) Quantification of the protein expression levels of p-STAT3 in NHEK. (D) Potential underlying mechanisms involved in gefitinib-induced barrier function disruption. ${ }^{* *} \mathrm{P}<0.01$ vs. the control group, $\mathrm{n}=3$. NHEK, normal human epidermal keratinocytes; STAT3, signal transducer and activator of transcription 3; p-, phosphorylated; ERK, extracellular-regulated kinase; EGF, epidermal growth factor; EGFR, epidermal growth factor receptor. 
into issues regarding skin toxicities and the clinical application of gefitinib. Furthermore, the gefitinib-induced barrier function disruption in NHEK was indicated that it may partially be due to Src and STAT3 pathway inhibition. Therefore, a novel potential EGFR-Src-STAT3-ERK signaling cascade was proposed. These novel mechanisms are in accordance with previous reports $(36,37)$; however, they provide novel insight into the prevention of skin barrier dysfunction caused by EGFR-TKIs. Since gefitinib belongs to the family of EGFR-TKIs, the research on gefitinib may additionally indicate the involvement of other members in this family (38). It is noteworthy that PP2 and AZD0530 inhibit various Src family kinases including c-Src, Lck, c-YES, Lyn, Fyn, Fgr and Blk. Thus, the other Src family pathways that may be involved in gefitinib-induced skin toxicities require further investigations in the future.

In conclusion, it was determined that the mechanisms underlying the skin toxicities of gefitinib may involve CLDN1 and 4 downregulation and CLDN2 upregulation in NHEK. Additionally, the Src and STAT3 pathways were identified to be involved in gefitinib-induced barrier function disruption in the NHEK. The present data may provide a novel strategy for improving skin toxicity of gefitinib in patients with lung cancer.

\section{Acknowledgements}

Not applicable.

\section{Funding}

The present study was supported by the National Natural Science Foundation of China (grant no. 81271743).

\section{Availability of data and materials}

All datasets used and/or analyzed during the present study are available from the corresponding author on reasonable request.

\section{Authors' contributions}

YWa and LX conducted NHEK cell culture, performed the MTT assay and assisted with manuscript preparation. SZ and JB executed TER and Pa\% detection. YWu and JQ prepared RNA samples and conducted RT-qPCR. XJ was responsible for immunoblotting. DZ completed the immunohistochemical assay. YD analyzed and interpreted the experiment data. HF designed the study, investigated the potential cell signaling pathways and was the major contributor of this manuscript. All authors read and approved the final manuscript.

\section{Ethics approval and consent to participate}

Not applicable.

\section{Patient consent for publication}

Not applicable.

\section{Competing interests}

The authors declare that they have no competing interests.

\section{References}

1. Ehmann LM, Ruzicka T and Wollenberg A: Cutaneous side-effects of EGFR inhibitors and their management. Skin Therapy Lett 16: 1-3, 2011.

2. Baas JM, Krens LL, Guchelaar HJ, Ouwerkerk J, de Jong FA, Lavrijsen AP and Gelderblom $\mathrm{H}$ : Recommendations on management of EGFR inhibitor-induced skin toxicity: A systematic review. Cancer Treat Rev 38: 505-514, 2012.

3. Pomerantz RG, Mirvish ED and Geskin LJ: Cutaneous reactions to epidermal growth factor receptor inhibitors. J Drugs Dermatol 9: 1229-1234, 2010

4. Reck M and Gutzmer R: Management of the cutaneous side effects of therapeutic epidermal growth factor receptor inhibition. Onkologie 33: 470-479, 2010

5. Overgaard CE, Daugherty BL, Mitchell LA and Koval M: Claudins: Control of barrier function and regulation in response to oxidant stress. Antioxid Redox Signal 15: 1179-1193, 2011.

6. Morita K, Miyachi Y and Furuse M: Tight junctions in epidermis: From barrier to keratinization. Eur J Dermatol 21: 12-17, 2011.

7. Kirschner N, Bohner C, Rachow S and Brandner JM: Tight junctions: Is there a role in dermatology? Arch Dermatol Res 302: 483-493, 2010.

8. Furuse M, Hata M, Furuse K, Yoshida Y, Haratake A, Sugitani Y, Noda T, Kubo A and Tsukita S: Claudin-based tight junctions are crucial for the mammalian epidermal barrier: A lesson from claudin-1-deficient mice. J Cell Biol 156: 1099-1111, 2002.

9. Hadj-Rabia S, Baala L, Vabres P, Hamel-Teillac D, Jacquemin E, Fabre M, Lyonnet S, De Prost Y, Munnich A, Hadchouel M, et al: Claudin-1 gene mutations in neonatal sclerosing cholangitis associated with ichthyosis: A tight junction disease. Gastroenterology 127: 1386-1390, 2004.

10. Turksen K and Troy TC: Barriers built on claudins. J Cell Sci 117: 2435-2447, 2004.

11. Tran QT, Kennedy LH, Leon Carrion S, Bodreddigari S, Goodwin SB, Sutter CH and Sutter TR: EGFR regulation of epidermal barrier function. Physiol Genomics 44: 455-469, 2012.

12. Livak KJ and Schmittgen TD: Analysis of relative gene expression data using real-time quantitative PCR and the 2(-Delta Delta C(T)) Method. Methods 25: 402-408, 2001.

13. Zhang J, Ni C, Yang Z, Piontek A, Chen H, Wang S, Fan Y, Qin Z and Piontek J: Specific binding of Clostridium perfringens enterotoxin fragment to Claudin-b and modulation of zebrafish epidermal barrier. Exp Dermatol 24: 605-610, 2015.

14. Adam AP: Regulation of endothelial adherens junctions by tyrosine phosphorylation. Mediators Inflamm 2015: 272858 , 2015.

15. Alsaffar H, Martino N, Garrett JP and Adam AP: Interleukin-6 promotes a sustained loss of endothelial barrier function via Janus kinase-mediated STAT3 phosphorylation and de novo protein synthesis. Am J Physiol Cell Physiol 314: C589-C602, 2018.

16. Sharma V, Singh SK, Anderson D, Tobin DJ and Dhawan A: Zinc oxide nanoparticle induced genotoxicity in primary human epidermal keratinocytes. J Nanosci Nanotechnol 11: 3782-3788, 2011.

17. Mikami D, Sakai S, Sasaki S and Igarashi Y: Effects of asterias amurensis-derived sphingoid bases on the de novo ceramide synthesis in cultured normal human epidermal keratinocytes. J Oleo Sci 65: 671-680, 2016.

18. Szöllósi AG, Gueniche A, Jammayrac O, Szabó-Papp J, Blanchard C, Vasas N, Andrási M, Juhász I, Breton L and Bíró T: Bifidobacterium longum extract exerts pro-differentiating effects on human epidermal keratinocytes, in vitro. Exp Dermatol 26: 92-94, 2017.

19. Dang NN, Pang SG, Song HY, An LG and Ma XL: Filaggrin silencing by shRNA directly impairs the skin barrier function of normal human epidermal keratinocytes and then induces an immune response. Braz J Med Biol Res 48: 39-45, 2015.

20. Woo SW, Rhim DB, Kim C and Hwang JK: Effect of standardized boesenbergia pandurata extract and its active compound panduratin A on skin hydration and barrier function in human epidermal keratinocytes. Prev Nutr Food Sci 20: 15-21, 2015.

21. Mullin JM, Laughlin KV, Ginanni N, Marano CW, Clarke HM and Peralta Soler A: Increased tight junction permeability can result from protein kinase $\mathrm{C}$ activation/translocation and act as a tumor promotional event in epithelial cancers. Ann N Y Acad Sci 915: 231-236, 2000

22. Flores-Benitez D, Rincon-Heredia R, Razgado LF, Larre I, Cereijido $\mathrm{M}$ and Contreras RG: Control of tight junctional sealing: Roles of epidermal growth factor and prostaglandin E2. Am J Physiol Cell Physiol 297: C611-C620, 2009. 
23. Flores-Benítez D, Ruiz-Cabrera A, Flores-Maldonado C, Shoshani L, Cereijido M and Contreras RG: Control of tight junctional sealing: Role of epidermal growth factor. Am J Physiol Renal Physiol 292: F828-F836, 2007.

24. Kojima T, Yamamoto T, Lan M, Murata M, Takano K, Go M, Ichimiya $\mathrm{S}$, Chiba $\mathrm{H}$ and Sawada N: Inhibition of MAP kinase activity moderates changes in expression and function of $\mathrm{Cx} 32$ but not claudin-1 during DNA synthesis in primary cultures of rat hepatocytes. Med Electron Microsc 37: 101-113, 2004

25. Furuse M, Fujita K, Hiiragi T, Fujimoto K and Tsukita S: Claudin-1 and -2: Novel integral membrane proteins localizing at tight junctions with no sequence similarity to occludin. J Cell Biol 141: $1539-1550,1998$

26. Amasheh S, Meiri N, Gitter AH, Schöneberg T, Mankertz J, Schulzke JD and Fromm M: Claudin-2 expression induces cation-selective channels in tight junctions of epithelial cells. J Cell Sci 115: 4969-4976, 2002.

27. Rosenthal R, Milatz S, Krug SM, Oelrich B, Schulzke JD, Amasheh S, Günzel D and Fromm M: Claudin-2, a component of the tight junction, forms a paracellular water channel. J Cell Sci 123 1913-1921, 2010

28. Muto S, Hata M, Taniguchi J, Tsuruoka S, Moriwaki K, Saitou M, Furuse K, Sasaki H, Fujimura A,Imai M, et al: Claudin-2-deficient mice are defective in the leaky and cation-selective paracellular permeability properties of renal proximal tubules. Proc Natl Acad Sci USA 107: 8011-8016, 2010.

29. Furuse M, Furuse K, Sasaki H and Tsukita S: Conversion of zonulae occludentes from tight to leaky strand type by introducing claudin-2 into Madin-Darby canine kidney I cells. J Cell Biol 153 263-272, 2001.

30. Colegio OR, Van Itallie CM, McCrea HJ, Rahner $\mathrm{C}$ and Anderson JM: Claudins create charge-selective channels in the paracellular pathway between epithelial cells. Am J Physiol Cell Physiol 283: C142-C147, 2002.
31. Colegio OR, Van Itallie C, Rahner C and Anderson JM: Claudin extracellular domains determine paracellular charge selectivity and resistance but not tight junction fibril architecture. Am J Physiol Cell Physiol 284: C1346-C1354, 2003.

32. Hou J, Gomes AS, Paul DL and Goodenough DA: Study of claudin function by RNA interference. J Biol Chem 281: 36117-36123, 2006.

33. Ikari A, Takiguchi A, Atomi K and Sugatani J: Epidermal growth factor increases clathrin-dependent endocytosis and degradation of claudin-2 protein in MDCK II cells. J Cell Physiol 226: 2448-2456, 2011.

34. Singh AB and Harris RC: Epidermal growth factor receptor activation differentially regulates claudin expression and enhances transepithelial resistance in Madin-Darby canine kidney cells. J Biol Chem 279: 3543-3552, 2004.

35. Findley MK and Koval M: Regulation and roles for claudin-family tight junction proteins. IUBMB Life 61: 431-437, 2009.

36. García-Hernández V, Flores-Maldonado C, Rincon-Heredia R, Verdejo-Torres O, Bonilla-Delgado J, Meneses-Morales I, Gariglio P and Contreras RG: EGF regulates claudin-2 and -4 expression through Src and STAT3 in MDCK cells. J Cell Physiol 230: 105-115, 2015.

37. Singh AB, Sharma A and Dhawan P: Claudin-1 expression confers resistance to anoikis in colon cancer cells in a Src-dependent manner. Carcinogenesis 33: 2538-2547, 2012.

38. Ogawa Y, Kiba T, Nakano K, Fujiwara K, Taniguchi $H$, Hosokawa A, Nakashima T, Kimoto S, Kajiume S, Okada Y, et al: Prospective study of biotin treatment in patients with erythema due to gefitinib or erlotinib. Gan To Kagaku Ryoho 41: 517-522, 2014 (In Japanese). 